\title{
An Immediate Real Time Detection and Prevention of Double-Spending in Electronic Cash Payment System
}

\author{
Princewill Aigbe \\ Department of Mathematics and Computer \\ Science \\ College of Natural and Applied Sciences, Western \\ Delta University, Oghara, Nigeria
}

\author{
Andrew Onibere \\ Department of Computer Science \\ Faculty of Physical Sciences. \\ University of Benin, Benin, Nigeria
}

\begin{abstract}
The introduction electronic commerce has created new financial needs that in many cases cannot be effectively fulfilled by the traditional payment systems. The success of electronic commerce business depends on the credibility of the available electronic payment systems. Electronic cash payment is one electronic payment systems developed to settle payments electronically, but suffers the problem of double-spending fraud. This paper identifies the possible causes of double-spending fraud and presents techniques to mitigate this type of fraud. These techniques involve the modification of existing electronic cash payment system, and a demonstration of the modified system to determine its double-spending fraud resistant capability.
\end{abstract}

\section{General Terms}

Electronic cash payment system, electronic commerce

\section{Keywords}

eCash, algorithm, registration certificate, double-spending, fraud resistant capability, merchant, real time, entity, public key infrastructure, subscriber registration authority.

\section{INTRODUCTION}

An electronic cash payment system allows users to withdraw eCash, represented as bit strings from a bank, and spend those eCash anonymously at participating merchants, so that the bank cannot link spent eCash to the user who withdraws them. A variety of schemes with various security properties have been proposed for this purpose, but because strings of bits are inherently copyable, they must all deal with the problem of double-spending. Double-spending is the failure of electronic cash payment systems allowing the possibility to spend the same or given eCash twice. Different electronic cash payment schemes have been proposed with various security features to prevent or fight against double-spending.

[1] proposed the first untraceable electronic cash system based on blind signature which allows the requester to obtain a message signature from a signer without revealing the message content and makes the signer unable to link any signed message to its signature. This initial proposal required an online broker to clear eCash before merchants could provide their services, to protect against double-spending. This solution was regarded as a cut and choose technology, and very expensive.

[2] improved on [1] by proposing an electronic cash payment scheme in which each eCash contains a hidden reference to the eCash owner. If the is spent once it is untraceable, while spending the eCash twice allows the broker to extract the identity hidden inside the eCash. [3]introduced two new concepts in protecting against doublespending. The two concepts are: i. Restrictive blind signatures to ensure traceability of double-
spending after transactions. The realisation of this concept
requires a great sacrifice in efficiency and questionable security.

ii.Wallets with observers guarantee prior restraint of doublespending, while still offering traceability of doublespenders after transactions in case tamper-resistant is compromised.

[4] proposed an electronic cash payment scheme in which every eCash generated is embedded with secret information. The secret information is used to verify any ecash that is double spent.

[5] proposed an electronic cash payment scheme with doublespending tracing based on elliptic curve cryptography. The scheme checks and traces double spending by requiring the merchant sends transcript of the execution of payment protocol to the bank, which verifies if that eCash has been double spent. In the payment protocol after the merchant sends challenge $d$ to the user, the user calculates three responses $\left(r_{1}, r_{2}, r_{3}\right)$ and sends them to the merchant. If the user spent the same coin twice then the merchant should send to user another challenge $d$ 'and user calculates another three responses $\left(r_{1}{ }^{\prime}, r_{2}{ }^{\prime}, r_{3}{ }^{\prime}\right)$ to the merchant. In the deposit protocol the merchant sends $\left(r_{1}, r_{2}, r_{3}\right)$ and $\left(r_{1}{ }^{\prime}, r_{2}{ }^{\prime}, r_{3}{ }^{\prime}\right)$ to the bank, and then the bank uses the responses to trace or reveal the identity of the user that double spent a given eCash.

[6] proposed electronic cash payment scheme that protects against double-spending by associating a pair of challenge $c_{s}$ and response $r_{c}$ keys to the transactions between a customer and merchant. The scheme uses the pair $\left(c_{s}, r_{c}\right)$ to extract the identification information of any customer that double spent a given ecash.

[7] proposed a scheme that provides for users' anonymity and detects double-spending by traceability. The proposed scheme attaches expiration date to eCash so that the banking system can manage its databases more efficiently.

[8] proposed an electronic payment scheme that allows the user to withdraw a single divisible eCash and spends the subeCash by dividing the value of the eCash. The scheme protects against double-spending by conducting a look up of the eCash's serial number in a table of previously spent eCash.

The electronic cash payment system used different techniques to fight against double-spending. The different technique used by electronic cash payment system also shown that doublespending occurs before its detection and a trace of the 
payment transaction is carried out to determine the double spender.

\section{CAUSES OF DOUBLE-SPENDING}

Double-spending fraud in electronic cash payment system occurred as a result of the following:

\subsection{Concurrent executing transactions}

The double spending fraud occurs when two or more concurrent executing transactions in a distributed environment read the old value of a variable (shared data) and then use it to calculate the new value.

Figure 1 shows a customer $\mathrm{C}$ with eCash token of 50 units performs two transactions with merchants $M_{1}$ and $M_{2}$ at the same time. In transaction $T_{i}$ with merchant $M_{1}$, customer $C$ pays 40 units with $\mathrm{eCash}_{\mathrm{ID}}$ :eCashValue(50) and retains 10 units while in transaction $\mathrm{T}_{i+1}$ with merchant $\mathrm{M}_{2}$, customer $\mathrm{C}$ pays 30 units with the same eCash ${ }_{\mathrm{ID}}$ :eCashValue(50) and retains 20 units.

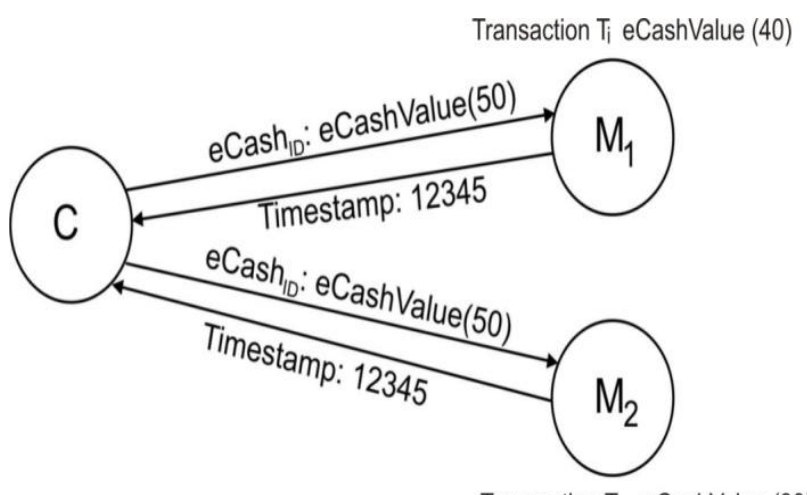

Transaction $\mathrm{T}_{i+1}$ eCashValue (30)

Figure 1: Two concurrent executing transactions with the same eCash:eCashValue(50)

The outcome of the two transactions shows that doublespending occurred as the accumulated units of $\mathrm{eCash}_{\mathrm{ID}}$ for the two transactions is more than the available units of $\mathrm{eCash}_{\mathrm{ID}}: \mathrm{eCashValue(50)}$ belonging to the customer. Both transactions have read the original units of $\mathrm{eCash}_{\mathrm{ID}}$ available to the customer before either writes the new updated units of eCash ${ }_{\text {ID }}$. This also shows that transaction $\mathrm{T}_{\mathrm{i}+1}$ should have not been successful as the new available units of $\mathrm{eCash}_{\mathrm{ID}}$ tokens after transaction $T_{i}$ is insufficient to meet or satisfy the transaction, and this is a mutual exclusion problem.

\subsection{Duplication of Electronic cash identification $\left(\mathrm{eCash}_{\mathrm{ID}}\right)$}

Electronic cash identifications ( $\left(\mathrm{eCash}_{\mathrm{ID}}\right.$ 's $)$ are duplicated when they are transferred from one system to another without removing them from the original system. This normally occur when there is a full system backup and drive ghosting or image creation of a system. A duplicate electronic cash $\mathrm{eCash}_{\text {ID }}$ can cause double-spending when the electronic cash system implementation does not track or authenticate whether or not electronic cash $\mathrm{eCash}_{\mathrm{ID}}$ have been spent by a customer or user before allowing a payment operation to be completed successfully.

Figure 2 shows duplicate copies of electronic cash identification $\left(\mathrm{eCash}_{\mathrm{ID}}\right.$ :eCashValue(60)) from customer $\mathrm{C}$ used to pay for goods or services from two merchants $\left(\mathrm{M}_{3}\right.$ and $\mathrm{M}_{4}$ ) with different timestamps. This happens because the electronic cash payment system implementation has no mechanism of identifying duplicate copies of electronic cash identifications $\left(\mathrm{eCash}_{\mathrm{ID}}\right.$ 's)
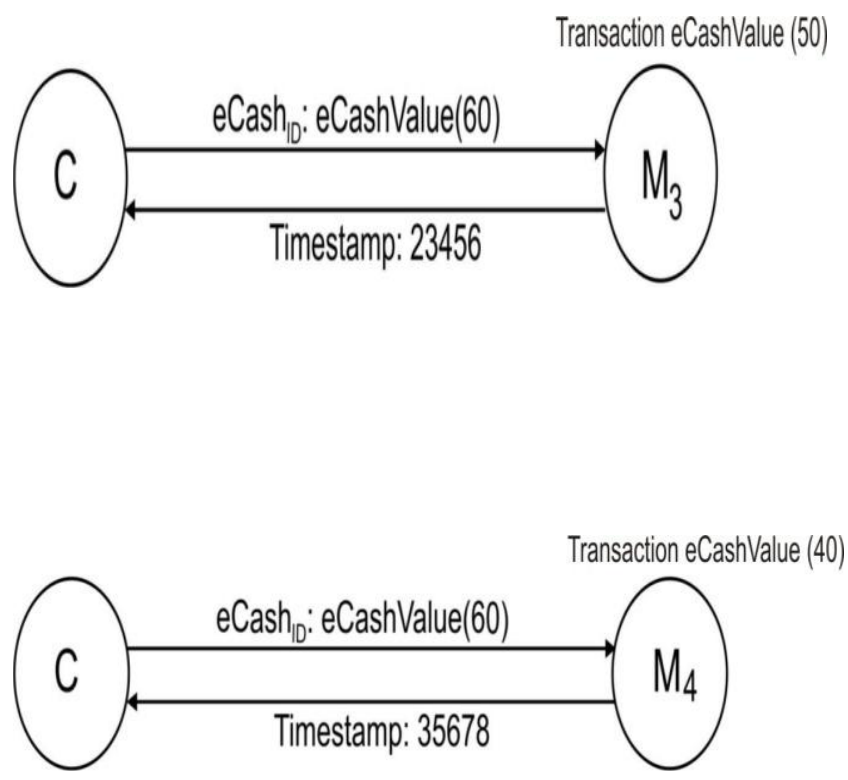

Figure 2: Duplicate copies ofeCash ${ }_{\mathrm{ID}}$ :eCashValue(60) used for two different transactions

\section{MECHANISMS FOR SOLVING THE DOUBLE-SPENDING FRAUD}

The identified causes of double-spending fraud can be addressed by the application of distributed mutual exclusion algorithm and the introduction of a new entity to the existing electronic cash payment model.

\subsection{Serialization of concurrent executing transactions}

Distributed mutual exclusion algorithms based on messagepassing will be implemented to coordinate the activities of concurrent executing transactions on a shared resource (shared data). Mutual exclusion is required to prevent interference and ensure consistency when accessing the shared resource. This means that the double spending fraud cannot happen if one transaction is performed before the other, because the later transaction will read updated value written by the earlier one, [9]

Since the serially equivalent interleaving of two transactions produces the same effect as a serial one, double spending fraud can be solved by means of serial equivalence. Each concurrent transaction employs the serialization technique in order to access and execute the shared data in critical section by distributed mutual exclusion mechanism [10].

For mutual exclusion (ME) to be enforced, the following requirements are essential:

i. At most one transaction may execute in the critical section,

(ME1: safety).

ii. Requests to enter and exit the critical section eventually succeed, (ME2: liveness). 
iii. If one request to enter the critical section happened-before another, then entry to the critical section is granted in that order,

(ME3: ordering).

A study of the different algorithms that implement mutual exclusion was investicated to select the algorithm with the best performance characteristics. These algorithms are of two categories:

\section{a. Non token-based Algorithms}

These algorithms require two or more successive rounds of message exchanges among the contending transactions. These algorithms are assertion based because a transaction can enter its critical section (CS) when an assertion defined on its local variables becomes true.

Mutual exclusion is enforced because the assertion becomes true only for one transaction at any given time. These are:

\section{i. Lamport's Algorithm \\ ii. Ricart and Agrawala's Algorithm \\ iii. Maekawa's voting Algorithm}

\section{b. Token-based Algorithms}

A unique token (i.e., a privilege message) is shared among the transactions. A transaction is allowed to enter its critical section if it possesses the token and it continues to hold the token until the execution of the critical section is over. These are:

\section{i. Suzuki-Kasami \\ ii. Singhal's Heuristic \\ iii. Raymond's tree-based Algorithm}

The performance of the various mutual exclusion algorithms is evaluated using the following criteria:

\section{i. Number of Messages per Request}

The total number of messages required to enter critical section (CS) is an important and useful parameter to determine the required network bandwidth for that particular algorithm.

\section{ii. Response Time, $(\mathbf{R})$}

The Response Time $\mathrm{R}$ is measured as the interval between the request of a transaction to enter a critical section (CS) and the time it finishes executing the critical section (CS). When the system is lightly loaded, twice the number of message transfer times and the execution time (E) of the critical section (CS) success results in light-load $=2 \mathrm{~T}+\mathrm{E}$ units. Under heavy load conditions, assuming at least one message is needed to transfer the access right from one transaction to another, then heavy-load $=\mathrm{w}(\mathrm{T}+\mathrm{E})$ where $\mathrm{w}$ is the number of waiting requests.

\section{iii. Synchronization Delay (S)}

The synchronization delay $\mathrm{S}$ is the time required for a transaction to enter a CS once another transaction finishes executing it. The minimum value of $S$ is one message transfer time $\mathrm{T}$, since it requires one message success to transfer the access rights to another transaction.

[11] carried out the evaluation of the performance characteristics of the two categories of distributed mutual exclusion algorithms as shown in table 1.
Table 1: Evaluation of performance characteristics of some selected distributed mutual exclusion algorithms

\begin{tabular}{|c|c|c|c|c|}
\hline $\begin{array}{l}\text { Non Token- } \\
\text { Based } \\
\text { Algorithms }\end{array}$ & $\begin{array}{c}\text { Messages } \\
\text { (Light-Load) }\end{array}$ & $\begin{array}{l}\text { Messages } \\
\text { (Heavy- } \\
\text { Load) }\end{array}$ & Response time & $\begin{array}{c}\text { Synchroni } \\
\text { zation } \\
\text { Delay }\end{array}$ \\
\hline Lamport & $3(\mathrm{~N}-1)$ & $3(\mathrm{~N}-1)$ & $2 \mathrm{~T}+\mathrm{E}$ & $\mathrm{T}$ \\
\hline $\begin{array}{c}\text { Ricart- } \\
\text { Agrawala }\end{array}$ & $2(\mathrm{~N}-1)$ & $2(\mathrm{~N}-1)$ & $2 \mathrm{~T}+\mathrm{E}$ & $\mathrm{T}$ \\
\hline Maekawa & $3 \sqrt{N}$ & $5 \sqrt{N}$ & $2 \mathrm{~T}+\mathrm{E}$ & $2 \mathrm{~T}$ \\
\hline $\begin{array}{c}\text { Token } \\
\text { Based } \\
\text { Algorithms }\end{array}$ & $\begin{array}{c}\text { Messages } \\
\text { Light-Load }\end{array}$ & $\begin{array}{l}\text { Messages } \\
\text { Heavy- } \\
\text { Load }\end{array}$ & $\begin{array}{c}\text { Response } \\
\text { time }\end{array}$ & $\begin{array}{c}\text { Synchroni } \\
\text { zation } \\
\text { Delay }\end{array}$ \\
\hline $\begin{array}{l}\text { Suzuki- } \\
\text { Kasami }\end{array}$ & $\mathrm{N}$ & $\mathrm{N}$ & $2 \mathrm{~T}+\mathrm{E}$ & $\mathrm{T}$ \\
\hline $\begin{array}{l}\text { Singhal's } \\
\text { Heuristic }\end{array}$ & $\mathrm{N} / 2$ & $\mathrm{~N}$ & $2 \mathrm{~T}+\mathrm{E}$ & $\mathrm{T}$ \\
\hline Raymond & $\log (N)$ & 4 & $\mathrm{~T} \log (\mathrm{N})+\mathrm{E}$ & $\mathrm{T} \log (\mathrm{N}) / 2$ \\
\hline
\end{tabular}

Table 1 shows that token-based mutual exclusion algorithms have superior performance characteristics because they required fewer number of messages to transfer access right from transaction to another however, they have one serious drawback. Their resiliency to failure is poor because if a transaction having token fails or token is lost in transit, a complex process of token regeneration or recovery has to be started [12].

Also from table 1, the Maekawa's voting algorithm has a superior performance in terms of the number of messages per entry and exit from the critical section but, with worse synchronization delay of $2 \mathrm{~T}$ (i.e., 2-message time). The Maekawa's voting algorithm is also deadlock prone. The Ricart-Agrawala (RA) algorithm is considered the most efficient non token-based mutual exclusion algorithms in distributed message-passing systems. The RA algorithm requires

2(N- 1) messages per critical section access with a synchronization delay of one message time, T. The RicartAgrawala (RA) algorithm totally satisfies the essential requirements of mutual exclusion implementation and has been tested in different applications, [13]. The RicartAgrawala (RA) distributed mutual exclusion algorithm is therefore selected for the implementation of mutual exclusion in solving double spending fraud in the modified electronic payment system.

\subsection{Control of duplicate eCash identification $\left(\mathrm{eCash}_{\mathrm{ID}}\right)$}

The various proposed electronic cash payment systems based on [1] model, checks for double-spending fraud after a transaction has been completed. If a transaction involves double-spending of $\mathrm{eCash}_{\mathrm{ID}}$, a trace of the transaction is conducted to determine the identity of the double spender.

Therefore, to check double-spending occurrence, an immediate real-time detection and prevention technique is 
required to successfully mitigate double-spending fraud in electronic cash payment system. This is done by introducing a new entity to the existing electronic cash payment system.

\subsubsection{The new Entity in the modified system}

The introduced new entity known as the subscriber registration authority (SRA) will be responsible for the following functions:

i. It generates and stores digital certificate containing key pair (private and public keys) for every participating entity.

ii. It mines or creates electronic cash tokens for the customers (subscribers) through a financial institution.

iii. It validates electronic cash tokens presented for payments.

iv. It invalidates electronic cash identifications $\left(\mathrm{eCash}_{\mathrm{ID}}\right)$.

v. It also authenticates every participating entity in the payment process.

\subsubsection{The other entities in the system are:}

\section{Merchant}

The merchant is an entity that provides a wide range of online services (e.g. academic services) to customers or subscribers (e.g., students).

\section{Customer (Subscriber)}

This is an entity that requests different online services (e.g. academic services) from the merchants.

\section{Financial Institution}

This is an entity that provides (or renders) financial services for the entities involved in the online payment system, e.g. bank.

The modified electronic cash payment system is shown in figure 3 :

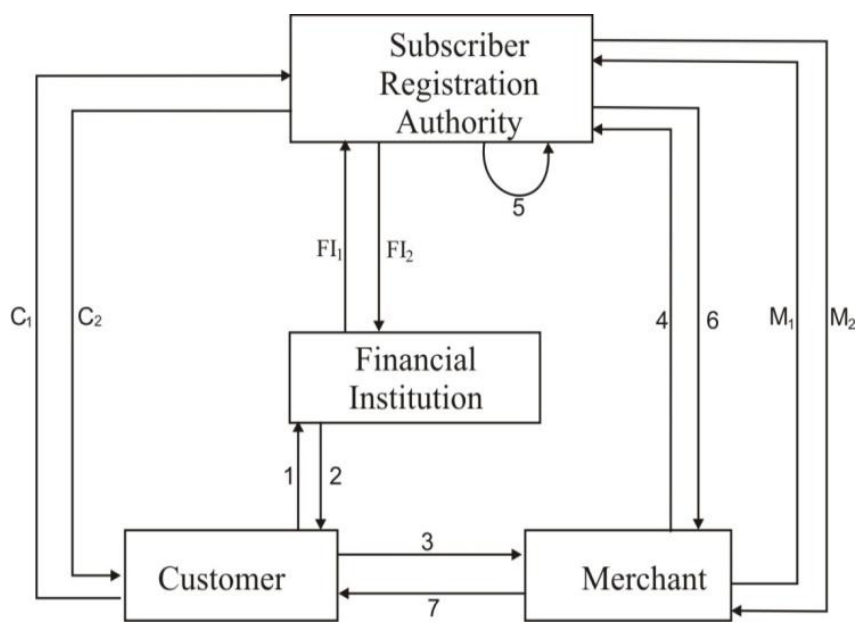

Figure 3: A block diagram of the modified electronic cash payment system where:

$\mathrm{C}_{1}$ Customer request for digital certificate

$\mathrm{C}_{2}$ Customer receives digital certificate

$\mathrm{M}_{1}$ Merchant request for digital certificate

$\mathrm{M}_{2}$ Merchant receives digital certificate

$\mathrm{FI}_{1}$ Financial institution request for digital certificate

$\mathrm{FI}_{2}$ Financial institution receives digital certificate

1. Customer sends digitally signed message to financial institution requesting for eCash.

2. Customer receives digitally signed message containing the requested eCash.

3. Customer initiates a transaction and receives payment request from the merchant.

4. Merchant generates and sends transaction notification message to subscriber registration authority

5. Subscriber registration authority receives and validates the transaction notification message to check for doublespending fraud.

6. Merchant receives transaction status message and generates a transaction acknowledgement report.

7. Customer receives transaction acknowledgement report and delivery of goods or services if successful.

\section{TWO MAJOR FEATURES OF THE MODIFIED ELECTRONIC CASH PAYMENT SYSTEM}

There are two major features of the modified system. These are:

\subsection{Entity registration}

Each participating entity registers with the subscriber registration authority (SRA) to obtain a subscriber registration certificate (SRC). A subscriber registration certificate binds a set of data items of a subscriber to a public key. It provides the means to know whether or not a public key does belong to a particular entity.

\subsection{Mutual authentication of entities}

For mutual authentication and secured messages to be exchanged among the entities in the modified system, public key infrastructure (PKI) is required. This is provided by an appropriate digital signature algorithm. A public key infrastructure (PKI) enables users of a basically unsecure public network such as the Internet to securely and privately exchange data and money through the use of a public and a private cryptographic key pair that is obtained and shared through a trusted authority, [14]. The public key and private key pair is generated by digital signature schemes based on asymmetric design, and employ different mathematical techniques such as integer factorization problem, e.g. RSA; intractability of the discrete logarithm problem, e.g. EIGamal, DSA, Diffie-Hellman; and elliptic curve discrete logarithm problem, e.g. ECDSA, ECDH.

The application of a given digital signature scheme is selected based on some factors. The most viable of these factors is signature verification time, and RSA digital signature scheme has the best signature verification time, [15]. 
The generation or creation of digital signatures requires cryptographic hash functions. A cryptographic hash function is an algorithm takes a group of characters (called a key) and maps it to a value of a certain length (called a hash value or hash, or message digest). The hash value or message digest is representative of the original string of characters, but is normally smaller than the original. One of the most secure hash functions used today is SHA-1 [16]. SHA-1 is a cryptographic hash function designed by the United States National Security Agency and is a U.S. Federal Information Processing Standard published by the United States NIST. SHA stands for "secure hash algorithm". SHA-1 produces a 160-bit (20-byte) hash value. A SHA-1 hash value is typically rendered as a hexadecimal number, 40 digits long. It is selected to produce message digest for RSA digital signature algorithm for the following reasons:

i. It is very simple and fast in generating a hash value or message digest.

ii. It has greater resistance to attacks.

iii. It is widely used security applications and protocols such as TLS, SSL, IPsec, etc.

\section{APPLICATION OF THE MODIFIED ELECTRONIC CASH PAYMENT SYSTEM IN A TRANSACTION}

The steps involve in the application of the modified electronic cash payment system in a payment transaction process are highlighted in sections 5.1 and 5.2. These steps are represented in algorithms.

\subsection{Entity registration process}

The first step in the application of the modified system in a transaction is for an entity registration process with subscriber registration authority. This means that all participating entities (i.e., customer, merchant, and Bank) wishing to use eCash as a means of payment for goods and services online must registered with subscriber registration authority to obtain a certificate. Algorithm 1 shows the algorithm for subscriber registration process.

Algorithm 1: Subscriber registration process

1. Collects(relevantdata); from the entity

2. Captures (relevantdata)

3. Generates (subscriberRegistrationCertificate)

4.Sends (subscriberRegistrationCertificate) $\{$ to requested entity\}

The subscriber registration certificate contains the following:

$\mathrm{SRC} \rightarrow\left(\mathrm{VRC}, \mathrm{CSN}, \mathrm{SAI}, \mathrm{IN}, \mathrm{PK}_{\mathrm{SRA}}, \mathrm{V}, \mathrm{EN}, \mathrm{PK}, \mathrm{P}\right.$, ACOUNT $\left._{\text {ID }}, \mathrm{ES}\right)$

where

VRC is the version of the subscriber registration certificate

$\mathrm{CSN}$ is certificate serial number

SAI signature algorithm identifier

IN is issuer name

$\mathrm{PK}_{\mathrm{SRA}}$ is issuer public key

$\mathrm{V}$ is the validity period of the certificate

$\mathrm{EN}$ is entity name

PK is entity public key

$\mathrm{P}$ is entity private key
ACCOUNT $_{\text {ID }}$ is entity account identification

ES is entity signature

Having obtained a registration certificate, the customer can now apply to a participating bank to request or purchase eCash by generating and sending a digitally signed message to the bank. Algorithm 2 shows the algorithm for eCash request.

Algorithm 2: eCash request message

1. requests $\left(e \mathrm{eCash}_{\mathrm{RM}}\right)\left\{\mathrm{eCash}_{\mathrm{RM}}\right.$ is electronic cash request message)

2. computes $\mathrm{CDS}=($ hashf $(\mathrm{eCashRM}) \mathrm{PC} *(\bmod \mathrm{n})\{\mathrm{PC}$ is customer's private key\}

3. Signs (eCashRM)

4. Sends (eCashRM) \{to financial institution \}

The signed electronic cash request message sent by customer contains the following items of data:

$\mathrm{eCash}_{\mathrm{RM}} \rightarrow$ (Account $_{\mathrm{ID}}, \mathrm{eCash}_{\mathrm{V}}, \mathrm{PK}_{\mathrm{C}}, \mathrm{C}_{\mathrm{DS}}$, Timestamp),

where

Account $_{\mathrm{ID}}$ is customer's account identification

$\mathrm{eCash}_{\mathrm{V}}$ is the value of electronic cash in units of a given currency

$\mathrm{PK}_{\mathrm{C}}$ is customer's public key

Timestamp is date and time of customer message

$\mathrm{C}_{\mathrm{DS}}$ is customer digital signature

When the financial institution received the signed message from the customer, it checks for message authenticity (i.e., if the message is sent by the claimed customer) as in the steps of algorithm 3 .

Algorithm 3: Verification of eCash message

1. Computes $\mathrm{h}_{\mathrm{c}}=\left(\mathrm{C}_{\mathrm{DS}}\right)^{\mathrm{PK}_{\mathrm{C}} *(\bmod \mathrm{n})}$ \{PKC is customer's public key\}

2. if $h_{C}=\operatorname{hashf}\left(e C a s h_{R M}\right) ; h_{c}$ is hash value of customer's digital signature

$$
\begin{aligned}
& \text { i. } \operatorname{accepts}\left(\mathrm{eCash} \mathrm{RM}_{\mathrm{M}}\right) \\
& \text { ii. computes } \mathrm{FI}_{\mathrm{DS}}=\left(\operatorname{hashf}\left(\mathrm{eCash} \mathrm{RM}_{\mathrm{R}}\right)\right)^{\mathrm{P}_{\mathrm{FI}}} *(\bmod \mathrm{n})\{\mathrm{PFI} \text { is }
\end{aligned}
$$

iii. signs (eCash $\left.\mathrm{RM}_{\mathrm{RM}}\right)$

iv. forwards(eCashRM) \{to subscriber registration authority (SRA)

3. else

message not authentic

The message forwarded by the financial institution to the subscriber registration authority is of the form: signed eCashMessage $\rightarrow\left(\mathrm{eCash}_{\mathrm{RM}}, \mathrm{PK}_{\mathrm{FI}}, \mathrm{FI}_{\mathrm{DS}}\right.$, Timestamp), where

$\mathrm{PK}_{\mathrm{FI}}$ is financial institution's public key

$\mathrm{FI}_{\mathrm{DS}}$ is financial institution's public key

Timestamp is date and time of message generation 
When the subscriber registration authority received the message from the financial institution, it verifies and mines eCash as requested. The required steps are shown in algorithm 4.

Algorithm 4: Generates eCash

1. receives $\left(\mathrm{eCash}_{\mathrm{RM}}\right)$ \{from financial institution

2. $\operatorname{computesh}_{\mathrm{fi}}=\operatorname{hashf}\left(\mathrm{FI}_{\mathrm{DS}}\right)^{\mathrm{PKFI}} \mathrm{x}(\bmod \mathrm{n})$

3. determines the existence of subscriber's account ${ }_{\text {ID }}$ in the message

4. if $\mathrm{h}_{\mathrm{fi}}=\operatorname{hashf}\left(\mathrm{eCash}_{\mathrm{RM}}\right)$ and account $_{\mathrm{ID}}$ exists

i. accepts $\left(e C a s h_{R M}\right)$

ii. generates (eCash)

iii. computes SRADS $=($ hashf $(\mathrm{eCash}) \mathrm{PSRA} \times(\bmod \mathrm{n})$ \{PSRA is SRA private key\}

iv. sends (eCash) \{to financial institution $\}$

5. else

message is invalid and therefore, rejected

The eCash message generated by the subscriber registration authority is of the form:

eCashmessage $\rightarrow$ (account $_{\text {ID }}$, eCash ID $_{\text {eCash }}$, eCash SECRET $_{\text {, }}$ $\mathrm{PK}_{\mathrm{SRA}}, \mathrm{SRA}_{\mathrm{DS}}$, Timestamp), where

account $_{\mathrm{ID}}$ is customer's account identification

$\mathrm{eCash}_{\mathrm{ID}}$ is electronic cash identification

$\mathrm{eCash}_{\mathrm{V}}$ is eCash currency unit value

eCash $_{\text {SECRET }}$ is eCash protected code

$\mathrm{PK}_{\mathrm{SRA}}$ is subscriber registration authority's public key

$\mathrm{SRA}_{\mathrm{DS}}$ is subscriber registration authority's digital signature

Timestamp is date and time of eCash generation

On receiving the eCash message, the financial institution verifies the authenticity of the message from the subscriber registration authority as shown by the steps in algorithm 5 .

Algorithm 5: eCash message verification

1. computesh $_{\text {sra }}=\left(\mathrm{SRA}_{\mathrm{DS}}\right)^{\mathrm{PK} \mathrm{SRA}} \mathrm{x}(\bmod \mathrm{n})$

2. if $\mathrm{h}_{\mathrm{SRA}}=\operatorname{hashf}(\mathrm{eCash})$

i. eCash message is authentic

ii. deposits (eCash) \{in customer's account

iii. sends (ecash notification) \{to customer

3. else

eCash message is invalid

Finally, the customer receives the eCash requested.

\subsection{Online Payment Procedure for goods and services}

A customer visits a merchant store via the web to request goods or services as in algorithm 6 .

Algorithm 6: Customer initiates a transaction

1. initiates(transaction)

2. invoke serialisation(transactions) \{using selected mutual exclusion algorithm\}

When the merchant receives the transaction, it generates a payment request for the customer as shown in algorithm 7 .
Algorithm 7: Generation of payment request

1. Generates (paymentRequest) \{with the necessary parameters $\}$

2. computes $\mathrm{M}_{\mathrm{DS}}=(\text { hashf }(\text { paymentRequest }))^{\mathrm{Pm}} \mathrm{x}(\bmod \mathrm{n})$

3. signs (paymentRequest)

4. sends (paymentRequest) \{with digital signature $\left(\mathrm{M}_{\mathrm{DS}}\right)$ \}

The digitally signed payment request sent by merchant to the customer is of the form:

PaymentRequest $\rightarrow\left(\mathrm{PR}_{\mathrm{ID}}, \mathrm{M}_{\mathrm{ID}}, \quad \mathrm{T}_{\mathrm{A}}, \quad \mathrm{T}_{\mathrm{D}}, \quad \mathrm{PK}_{\mathrm{M}}, \mathrm{M}_{\mathrm{DS}}\right.$, Timestamp), where

$\mathrm{PR}_{\mathrm{ID}}$ is payment request identification

$\mathrm{M}_{\mathrm{ID}}$ is merchant identification

$\mathrm{T}_{\mathrm{A}}$ is transaction amount to be paid

$\mathrm{T}_{\mathrm{D}}$ is transaction description

$\mathrm{PK}_{\mathrm{M}}$ is merchant's public key

$\mathrm{M}_{\mathrm{DS}}$ is merchant's digital signature

Timestamp is date and time of payment request generation

On receiving the payment request from the merchant, the customer performs message verification process as shown in algorithm 8.

Algorithm 8: Verification of payment request and generation of payment grant message

1. computes $h_{m}=\left(M_{D S}\right)^{P K M} \times(\bmod n)$

2. if $\mathrm{h}_{\mathrm{m}}=($ hashf(paymenRequest)) ; payment request is authentic

i. accepts(paymentRequest)

ii. selects(eCash $\left.{ }_{\text {ID }}\right)$

iii. computes $\mathrm{CDS}=($ hashf $($ paymentGrant $)) \quad$ \{generates payment request

iv. signs (paymentGrant)

v. sends (paymentGrant) \{to merchant

3. else

payment request is invalid and not authentic

The payment grant message sent by the customer to the merchant consists of the following parameters:

paymentGrant $\rightarrow$ (Account $_{\mathrm{ID}}$, eCash ID $_{\mathrm{ID}}$ eCash SECRET $_{\text {, }} \mathrm{PK}_{\mathrm{C}}$, $\mathrm{C}_{\mathrm{DS}}$, Timestamp), where

Account $_{\text {ID }}$ is customer's account identification

$\mathrm{eCash}_{\mathrm{ID}}$ is electronic cash identification

$\mathrm{eCash}_{\text {SECRET }}$ is eCash protected code

$\mathrm{PK}_{\mathrm{C}}$ is customer's public key

$\mathrm{C}_{\mathrm{DS}}$ is customer's digital signature

Timestamp is date and time of payment grant message generation

The merchant receives payment grant message from customer and performs the actions in algorithm 9 .

Algorithm 9: Verification of payment grant message and generation of transaction notification message.

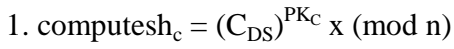

2. if $h_{c}=($ hashf(paymentGrant $\left.)\right)$

i. accepts (paymentGrant) 
ii.computes $\mathrm{M}_{\mathrm{DS}}=($ hashf(transactionNotification $\left.)\right)^{\mathrm{PM}} \mathrm{x}$ $(\bmod n)$

notification $\}$

$$
\text { \{generates transaction }
$$

iii. signs (transactionNotification)

iv.sends(transactionNotification) \{to SRA

3. else

payment request is invalid and not authentic

The transaction notification message sent to the subscriber registration authority consists of the following parameters:

transactionNotification $\rightarrow \quad$ Account $_{\mathrm{ID}}, \quad \mathrm{M}_{\mathrm{ID}}, \quad \mathrm{eCash}_{\mathrm{ID}}$, $\mathrm{eCash}_{\mathrm{SECRET}}, \mathrm{PK}_{\mathrm{M}}, \mathrm{M}_{\mathrm{DS}}$, Timestamp),

where Account $_{\text {ID }}$ is customer's account identification

$\mathrm{M}_{\mathrm{ID}}$ is merchant's identification

$\mathrm{eCash}_{\mathrm{ID}}$ is electronic cash identification

eCash $_{\text {SECRET }}$ is eCash protected code

$\mathrm{PK}_{\mathrm{M}}$ is merchant's public key

$\mathrm{M}_{\mathrm{DS}}$ is merchant's digital signature

Timestamp is date and time of transaction notification message generation

Subscriber registration authority receives and validates the transaction notification message in the steps of algorithm 10 .

Algorithm 10: Verification of transaction notification message and generation of transaction status report.

1. computes $\mathrm{h}_{\mathrm{m}}=\left(\mathrm{M}_{\mathrm{DS}}\right)^{\mathrm{PKM}} \mathrm{x}(\bmod \mathrm{n})$

2. if $\mathrm{hm}=($ hashf $($ transactionNotification $))$

2.1. accepts (transactionNotification)

2.2. if eCash $\mathrm{ID}_{\mathrm{ID}}$ matches eCash $\mathrm{SECRET}_{\mathrm{S}}$

i. generates(new secret)

ii. reassigns (new secret) \{to the $\left.\mathrm{eCash}_{\mathrm{ID}}\right\}$

iii. changes(ownership of $\mathrm{eCash}_{\mathrm{ID}}$ ) $\left\{\right.$ to $\left.\mathrm{M}_{\mathrm{ID}}\right\}$

iv. records $\left(\mathrm{eCash}_{\mathrm{ID}}\right.$ ownership exchange) $\{$ in transaction $\log$ \}

\section{v. generates (transactionStatus)}

vi.computes $\mathrm{SRA}_{\mathrm{DS}}=(\text { hashf }(\text { transactionStatus }))^{\mathrm{P}_{\mathrm{SRA}} \mathrm{X}}$ $(\bmod n)\{$ PSRA is subscriber registration authority's private key\}

vii. signs (transactionStatus)

viii. sends (transactionStatus) \{to merchant

2.3. else

\section{i. eCash SECRET $_{\text {has changed }}$}

ii. $\mathrm{eCash}_{\mathrm{ID}}$ has been spent \{immediate detection of double- spending attempt $\}$

prevented
iii.
terminates(transaction)
\{double-spending

iv. generates (transactionStatus) $(\bmod n)$

v. computes $S R A_{D S}=(\text { hashf }(\text { transactionStatus }))^{P_{\text {SRA }}} x$

vi. signs (transactionStatus)

vii. sends (transactionStatus) \{to merchant\}

3. else transaction notification message is invalid hence, not authentic

The transaction status message sent to the merchant consists of the following parameters:

transactionStatus $\rightarrow\left(\mathrm{T}_{\text {STATUS }}\right.$, Account $_{\mathrm{ID}}, \mathrm{NeCash}_{\mathrm{ID}}$, $\mathrm{NeCash}_{\text {SECRET }}, \mathrm{PK}_{\mathrm{SRA}}, \mathrm{SRA}_{\mathrm{DS}}$, Timestamp), where

$\mathrm{T}_{\text {STATUS }}$ is transaction status

Account $_{\text {ID }}$ is customer's account identification

$\mathrm{NeCash}_{\text {ID }}$ is new eCash identification

$\mathrm{NeCash}_{\text {SECRET }}$ is new eCash protected code

$\mathrm{PK}_{\mathrm{SRA}}$ is subscriber registration authority's public key

SRA $_{\mathrm{DS}}$ is subscriber registration authority's digital signature

Timestamp is date and time of transaction status message generation

When the merchant receives the transaction status message, it validates the message as shown in algorithm 11.

Algorithm 11: Verification of transaction status message and generation of transaction acknowledgement report

1. computesh $_{\text {sra }}=\left(\mathrm{SRA}_{\mathrm{DS}}\right)^{\mathrm{PK} \text { SRA }} \mathrm{x}(\bmod \mathrm{n})$

2. if $\mathrm{h}_{\text {sra }}=($ hashf(transactionStatus $\left.)\right)$

2.1. accepts (transactionStatus)

2.2. if transactioStatus is successful

i. merchant deposits $(\mathrm{eCash}$ ID $)$

$\left.\mathrm{eCash}_{\text {SECRET }}\right\}$

\{with the new assigned

ii. generates (transactionAcknowledgement)

iii. computes MDS =

(hashf(transactionAcknowledgement) $\mathrm{x} \quad(\bmod \mathrm{n})$

iv. signs (transactionAcknowledgement)

v. sends (transactionAcknowledgement)

2.3. else

i. transactionStatus is unsuccessful

ii. discards $\left(\mathrm{eCash}_{\mathrm{ID}}\right)$

iii. computes MDS

(hashf(transactionAcknowledgement) $\mathrm{x}(\bmod \mathrm{n})$

iv. signs (transactionAcknowledgement)

customer\}

v. sends (transactionAcknowledgement)

\{to

3. else

transaction status is invalid and not authentic

The customer receives the transaction acknowledgement message and carries out validation in algorithm 12 .

Algorithm 12: Verification of transaction acknowledgement message

1. computesh $_{\mathrm{m}}=\left(\mathrm{M}_{\mathrm{DS}}\right)^{\mathrm{PKM}} \mathrm{x}(\bmod \mathrm{n})$

2. if $\mathrm{h}_{\mathrm{m}}=($ hashf(transactionAcknowledgement $\left.)\right)$

2.1. accepts (transactionAcknowledgement)

2.2. if status is successful merchant

i. removes $\left(\mathrm{eCash}_{\mathrm{ID}}\right)$ \{from wallet $\}$

ii. receives(goods or access contents) \{ sent by

else 
i. sends (transactionacknowledgement)

\{ to subscriber registration

authority

as a confirm

acknowledgement

request

message $\}$

3. else

invalid message and hence, not authentic

\section{CONCLUSION AND FUTURE WORK}

This presents a modified electronic cash payment system to check double-spending fraud by the techniques of distributed mutual exclusion algorithm and introduction of a new entity that mines and validates electronic cash, and a demonstration of the modified system in a transaction process to show the detection and prevention of double-spending in real time.

The future work combines the different techniques discussed in this paper to carry out a real life implementation of the proposed modified electronic cash payment system.

\section{REFERENCES}

[1] Chaum, D., (1982). Blind signature for untraceable payments. Proceeding of the Annual International Cryptology conference on Advances in Cryptology (CRYTO`82), Santa Barbara, California.

[2] Chaum, D., Fiat A., Naor M. (1988). Untraceable Electronic Cash payments. Proceeding of the $8^{\text {th }}$ Annual International Cryptology conference on Advances in Cryptology (CRYTO‘88), Santa Barbara, California.

[3] Brands, S. (1993). An efficient off-line electronic cash system in wallets with observers. Proceeding of the $13^{\text {th }}$ Annual International Cryptology conference on Advances in Cryptology (CRYTO'88), Santa Barbara, California.

[4] Osipkor, E., Hopper, N., and Kin, Y. (2007). Combating double-spending using co-operative P2P systems. $27^{\text {th }}$ International conference on distributed computing systems (ICDCS '07), IEEE computer society.

[5] Elaalim, K. O., and Yang, S. (2010). Electronic cash system with double-spending tracing based on elliptic curve cryptography. Journal of Computational information Systems, 6(9), 2949 - 2957.
[6] Nashidi, T., Miyazaki, S., and Sakurai, K. (2011). Security analysis of E-Cash systems with malicious insider. Journal of Wireless mobile Networks, Ubiquittous Computing, and Depending Applications, 3(2), 55 - 71.

[7] Ziba, E., and Mehdi, E. (2011). A new untraceable off-line electronic cash system. Electronic Commerce and Applications, 10, 59-66.

[8] Yanling, H., Haibin, W., Xuguanf, C., and Xia, L. (2014). Efficient divisible E-cash based on the P-Signature. International Journal of Multimedia and Ubiquitous Engineering, 9(10), 153 - 168.

[9] Colouris, G., Dolkimore, J., and Kindberg, T. (2001). Distributed Systems: Design and Concepts (3rd ed.). Addison Wesley Publishers, Boston.

[10] Omrani, L., Rafinezhad, Z., and Keyvanpour, M. (2011). A function-based framework for classification and evaluation of mutual exclusion algorithms in distributed systems. International Journal of Computer Science and Security (IJCSS), 5(2), $890-908$.

[11] Bertier, M., Arantes, L., and Sens, P. (2006). Hierarchical token based mutual exclusion algorithms. IEEE Intemational Symposium on Cluster Computing and the Grid, 539 - 546.

[12] Swaroop, A., and Singh, K. (2007). A study of tokenbased algorithms for distributed mutual exclusion. International Review on Computers and Software (I. RE. CO. S), 2(4)

[13] Gupta, A., Reddy, B., Udayan, G., and Ashish, K. (2012). A permission-based clustering mutual exclusion algorithms in mobile ad-hoc networks. International Journal of Engineering Research and Applications, 2(4), $019-026$

[14] Chokhani, E., Carlisle, A., and Lloyd, S. (2010). Internet X.509 Public Key Infrastructure: Certificate Policy and Certification Practices Framework. Orion Security Solutions, Inc.

[15] Lenstra A., and Verheul E. (2005). Selecting Cryptographic Key Sizes. Journal of Cryptology, 14.

[16] Stevens, M. (2012). Attacks on hash functions and applications. IpaskampDrukkers, Amsterdam. 